\title{
Characterization of Ethylene-mediated Curling of Japanese Radish (Raphanus sativus var. longipinnatus) Cotyledons
}

Yusuke Kubo

Ibaraki Prefectural Namiki Secondary School, 4-5-1 Namiki, Tsukuba, Ibaraki 305-0044, Japan; Department of Biological Science, School of Science, Nagoya University, Furo-cho, Chikusa-ku, Nagoya, Aichi 464-8602, Japan

\author{
Shinobu Satoh and Haruka Suzuki \\ Faculty of Life and Environmental Sciences, University of Tsukuba, 1-1-1 \\ Tennodai, Tsukuba, Ibaraki 305-8577, Japan
}

\section{Toshinori Kinoshita}

Division of Biological Science, Graduate School of Science, Nagoya University, Furo-cho, Chikusa-ku, Nagoya, Aichi 464-8602, Japan; Institute of Transformative Bio-Molecules (WPI-ITbM), Nagoya University, Furo-cho, Chikusa-ku, Nagoya, Aichi 464-8601, Japan

\section{Nobuyoshi Nakajima \\ Center for Environmental Biology and Ecosystem Studies, National Institute for Environmental Studies, 16-2 Onogawa, Tsukuba, Ibaraki 305-0053, Japan}

Additional index words. airtight, cell growth, cross section, epinasty, microscopic, toluidine blue, 1-MCP

\begin{abstract}
During the transport of vegetables, it is important to maintain quality. The cotyledons of Japanese radish (Raphanus sativus var. longipinnatus) sprouts curl during transport, lowering quality. It is known that ethylene causes the leaf curling of some true leaves by promoting cell growth on the adaxial side (epinasty); however, the mechanism of cotyledon curling is unknown. We investigated the effect of ethylene on cotyledon curling of Japanese radish sprouts. Curling was promoted by exogenous treatment with ethylene and repressed by treatment with 1-methylcyclopropene, an inhibitor of ethylene perception. Microscopic observation of ethylene-exposed curled cotyledons and normal cotyledons indicates that ethylene did not affect cell number but did inhibit transverse (lateral) cell growth on the abaxial side of the cotyledons, causing cotyledon curling through differential growth. Ethylene inhibition of cell growth on the abaxial side of leaves has not been reported before. We show a new mechanism responsible for curling.
\end{abstract}

Japanese radish sprouts are popular in Japanese food. They are easy to grow and nourishing, and they are often grown at home in Japan. Commercially, $2767 \mathrm{t}$ of Japanese radish sprouts is grown each year (Statistics Bureau of Japan, 2014) in plant factories. The seeds are sown on sponge mats, and when the hypocotyls elongate to $5 \mathrm{~cm}$ and the cotyledons open, the sprouts are packed in sealed containers and transported to market over

Received for publication 18 June 2019. Accepted for publication 29 Aug. 2019.

We thank Masanori Tamaoki and Motoyuki Ashikari for providing 1-MCP used in this work. We also thank Ayami Takizawa for her technical assistance. This study was mainly supported by the University of Tsukuba GFEST program, the Global Science Campus from Japan Science and Technology Agency. Y.K. sincerely thanks the Ibaraki Prefectural Namiki Secondary School.

N.N. is the corresponding author. E-mail: naka-320@ nies.go.jp.
Japan. In the store, the cotyledons may start to curl, which causes shoppers to avoid them. As curling is not seen during culture in open air, the presence of ethylene, which is known to cause leaf curling (Crocker et al., 1932; Crocker, 1948; Kang, 1979; Palmer, 1985), is suspected of causing epinasty, in which adaxial cells grow faster than abaxial cells.

Two theories of the mechanism of epinasty have been proposed. In one, ethylene affects auxin transport, causing the concentration on the adaxial side of petioles to become higher than that on the abaxial side, thus promoting unequal growth (Reid et al., 1981). In the other, ethylene directly promotes elongation on the adaxial side (Palmer, 1976; Ursin and Bradford, 1989). Both theories describe growth of cells on the adaxial side Palmer, 1976; Reid et al., 1981; Ursin and Bradford, 1989). Because most studies of epinasty used true leaves of tomato, the physiology of epinasty in other species and organs is unknown, notably in cotyledons of Japanese radish.
In this study, we examined the role of endogenous and exogenous ethylene in curling of Japanese radish cotyledons and found that ethylene build-up in airtight conditions causes curling. At the cellular level, ethylene did not affect cell division, but it did inhibit transverse (lateral) cell growth on the abaxial side, causing curling.

\section{Materials and Methods}

Plant materials and growth conditions. Seeds of Japanese radish (Raphanus sativus L. var. longipinnatus) were purchased from Nakahara Seed Product Co., Ltd. (Fukuoka, Japan). We sowed either 70 or 100 seeds in airtight containers, as described below, on paper towels moistened with $30 \mathrm{~mL}$ of distilled water. The containers were held at $25^{\circ} \mathrm{C}$ under a $12-\mathrm{h}$ photoperiod at $68 \mu \mathrm{mol} \cdot \mathrm{m}^{-2} \cdot \mathrm{s}^{-1}$ provided by a $32-\mathrm{W}$ fluorescent lamp (FHF32EXN-HX-S; HotaluX, Ltd., Tokyo, Japan).

Airtight and open air conditions. Seventy seeds were sown in a 1.5 -L polypropylene container $(158 \mathrm{~mm} \times 258 \mathrm{~mm} \times 94 \mathrm{~mm})$ with a lid (airtight condition) or without a lid (open air). At $7 \mathrm{~d}$ after sowing, ethylene in the containers and in ambient air was measured by gas chromatography, and all cotyledons were evaluated as "normal" (flat), "bending" (curved), or "curled" (edges in contact) (Fig. 1).

1-Methylcyclopropene (1-MCP) treatment. Seventy seeds were sown as above. We put $1.2 \mathrm{mg}$ of 1-MCP, which inhibits the recognition of ethylene by cell receptors (Sisler and Serek, 1997), in $18 \mu \mathrm{L}$ of water in a microtube, which was fixed in the container with sticky tape. The 1-MCP slowly vaporized and diffused within the container. At $7 \mathrm{~d}$ after sowing, we measured ethylene and evaluated cotyledon curling in four sealed 1-MCP containers and three sealed control containers.

Ethylene treatment. One hundred seeds were sown in an airtight 4.5 -L polypropylene container $(297 \mathrm{~mm} \times 213 \mathrm{~mm} \times 104 \mathrm{~mm})$. Into the sealed container, we injected $99.5 \%$ ethylene gas (GL Science, Tokyo, Japan) to achieve $0.89 \mu \mathrm{mol} \cdot \mathrm{L}^{-1}$. To disperse the ethylene, a lump of ice was put on a corner of the lid for $5 \mathrm{~min}$ to stir the air. At $10 \mathrm{~d}$ after sowing, we evaluated cotyledon curling.

Ethylene analysis by gas chromatography. At $7 \mathrm{~d}$ after sowing, $1 \mathrm{~mL}$ of gas from each container (or from the ambient air for open air) was collected in a syringe, and the concentration of ethylene was measured on a gas chromatograph (GC-8A Shimadzu, Kyoto, Japan) equipped with a glass column ( $3 \mathrm{~mm}$ i.d. $\times 1 \mathrm{~m})$ packed with $\mathrm{Al}_{2} \mathrm{O}_{3}$ (60 to 80 mesh) and a flame ionization detector. The temperature of the injector, the detector, and the column was $80{ }^{\circ} \mathrm{C}$.

Preparation of cotyledon sections. We prepared sections from three normal cotyledons in airtight condition, three curled cotyledons in ethylene treatment, three curled cotyledons in airtight condition, three normal cotyledons in 1-MCP treatment, and three normal cotyledons in open air condition. Cotyledons were thinly sectioned by microtome or 
linear slicer. For the microtome, cotyledons were fixed in ethanol-acetic acid (3:1) and then dehydrated through an ethanol series: $30 \%$ ethanol at $4{ }^{\circ} \mathrm{C}$ for $30 \mathrm{~min} ; 50 \%$ at $5{ }^{\circ} \mathrm{C}$ for $30 \mathrm{~min} ; 70 \%$ at room temperature for $30 \mathrm{~min}$; and then $90 \%, 95 \%$, and $99.5 \%$ at room temperature for 20 to $30 \mathrm{~min}$ each. The samples were embedded in Technovit 7100 resin (Heraeus Kulzer, Hanau, Germany) and cut into $20-\mu \mathrm{m}$ dorsoventral (vertical) sections on a microtome (RM2145; Leica Microsystems, Tokyo, Japan). The cell walls were stained with $0.1 \%(\mathrm{w} / \mathrm{v})$ toluidine blue (Sumiyoshi et al., 2014). For the linear slicer, cotyledons were embedded in $5 \%(\mathrm{w} / \mathrm{v})$ agar and cut into $40-\mu \mathrm{m}$ dorsoventral (vertical) sections on a linear slicer (PRO7; Dosaka Em Co., Ltd., Kyoto, Japan).

Measurements of cotyledon sections. One intact section was chosen from each cotyledon. Images of the sections were recorded through a light microscope (DMRB, Leica) on a digital CCD camera (Olympus Soft Imaging Solutions $\mathrm{GmbH}$, Munster, Germany). The images were printed on $\mathrm{A} 3$ paper for analysis of transverse and dorsoventral cell growth: we counted the mesophyll cells of the outermost layer in a line along the adaxial (upper) side (line 1) and the abaxial (lower) side (line 2) of each cotyledon half (Fig. 2A) and measured the length of each line. We calculated the cell widths on each side from these measurements.

To measure cells in the dorsoventral direction, we drew a line joining the vascular
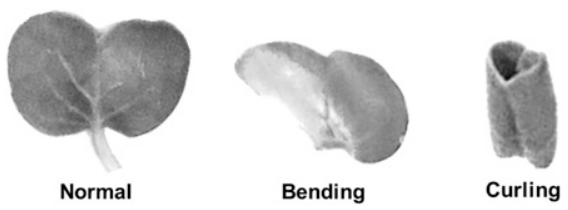

Fig. 1. Classification of normal, bending, and curled cotyledons of Japanese radish. bundles to separate the adaxial and abaxial sides and divided each cotyledon half into six equal parts (A-F; Fig. 2B). The mesophyll cells in a single file were counted along each of 10 equally spaced crossing lines on each side, and the leaf thickness was measured along each line. We calculated the cell thickness on each side from these measurements and then the means.

Statistical analysis. The proportions of each form of cotyledon was compared by chi-squared test and residual analysis, and the ethylene concentrations and cotyledon measurements were analyzed by $t$ test, considering $P<0.05$ as significant.

\section{Results}

Ethylene accumulated in airtight containers during cotyledon curling. To confirm that Japanese radish cotyledons curl in airtight containers, seedlings were grown in open air and airtight conditions and the proportions of normal, curled, and bending cotyledons was compared between conditions. In open air, $83 \%$ of 263 cotyledons were normal, $15 \%$ were bent, and $2 \%$ were curled (Fig. 3). In airtight storage, $45 \%$ of 544 cotyledons were normal, $36 \%$ were bent, and $19 \%$ were curled. In all, differences were significant $(P<0.05)$; there were fewer normal and more curled cotyledons in airtight storage than in open air (Fig. 3). Thus, cotyledons of Japanese radish curled more in airtight storage than in open air.

This phenomenon resembles leaf epinasty caused by ethylene. This phenomenon was possibly caused by the ethylene accumulated in the container. Therefore, we determined the concentration of ethylene in airtight condition. At $7 \mathrm{~d}$ after planting, the concentration of ethylene in container of "open air" and "airtight control" were measured using gas chromatography (Table 1). No ethylene was detected in open air but $3.7 \mathrm{nmol} \cdot \mathrm{L}^{-1}$ in airtight storage (Table 1). Thus, endogenously produced ethylene accumulated in the airtight containers.

1-Methylcyclopropene inhibited cotyledon curling. In airtight condition, Japanese radishes were treated with 1-methylcyclopropene (1-MCP), which is a volatile ethylene antagonist. After the treatment was ended, the cotyledons were classified into three categories: normal, bending, and curling. The proportion of each category was compared between "airtight control" and "1-MCP" (Fig. 3). In the control, $45 \%$ of 544 cotyledons were normal, $36 \%$ were bent, and $19 \%$ were curled (Fig. 3). In 1-MCP, $68 \%$ of 260 cotyledons were normal, $22 \%$ were bent, and $10 \%$ were curled. In all, differences were significant $(P<0.05)$; there were more normal and fewer curled cotyledons in 1-MCP than in the airtight control, despite the presence of ethylene (Fig. 3; Table 1). Thus, the inhibition of endogenous ethylene reception reduced cotyledon curling.

Exogenously applied ethylene promoted cotyledon curling. To investigate whether ethylene treatment causes cotyledon curling, we injected ethylene into airtight containers. After the treatment was over, the cotyledons were classified into three categories: normal, bending, and curling. The proportion of each category was compared between "airtight control" and "ethylene" (Fig. 4). In the airtight control, $43 \%$ of 824 cotyledons were normal, $37 \%$ were bent, and $20 \%$ were curled (Fig. 4). In ethylene, $22 \%$ of 845 cotyledons were normal, $43 \%$ were bent, and $35 \%$ were curled. In all, differences were significant $(P<0.05)$; there were fewer normal and more curled cotyledons in ethylene than in the airtight control (Fig. 4). Thus, exogenously applied ethylene promoted cotyledon curling.

Ethylene inhibited the growth of abaxial cells in curled cotyledons. We counted the number of cells on the adaxial and abaxial
A

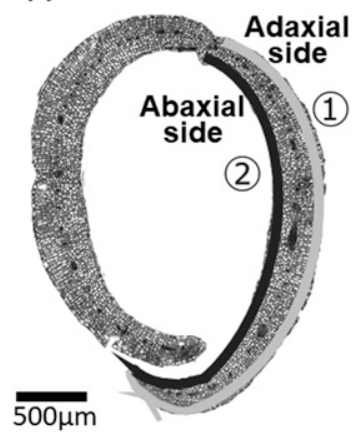

B

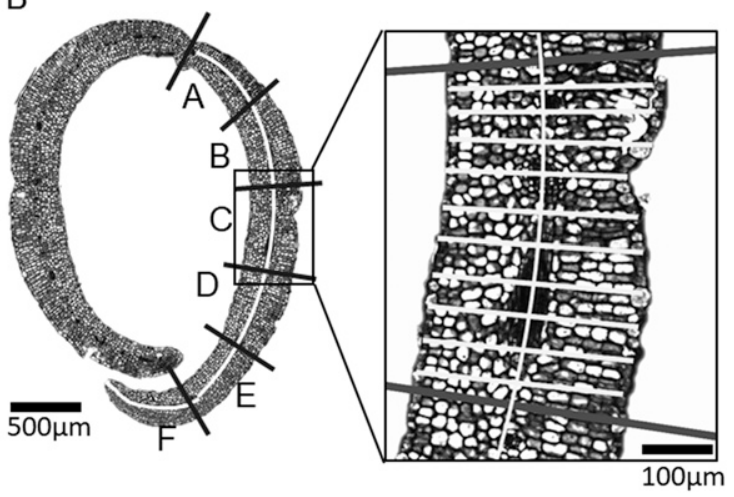

Fig. 2. Measurement of cross-section of cotyledons. Cotyledons were fixed in ethanol-acetic acid, dehydrated in ethanol, embedded in resin, cut to $20 \mu \mathrm{m}$ in the dorsoventral direction, and stained with toluidine blue. (A) Measurement of cell growth in transverse direction. Lengths of adaxial (gray) and abaxial (black) lines were measured. Mesophyll cells of the outermost layer were counted along the lines. (B) Measurement of cell growth in dorsoventral direction. The white line passing through the vascular bundles separates the adaxial and abaxial sides. The dark lines separate each side into six equal parts (A-F). Mesophyll cells were counted along each of the 10 equally spaced white lines shown in the enlargement on each side, and the thickness was also measured.

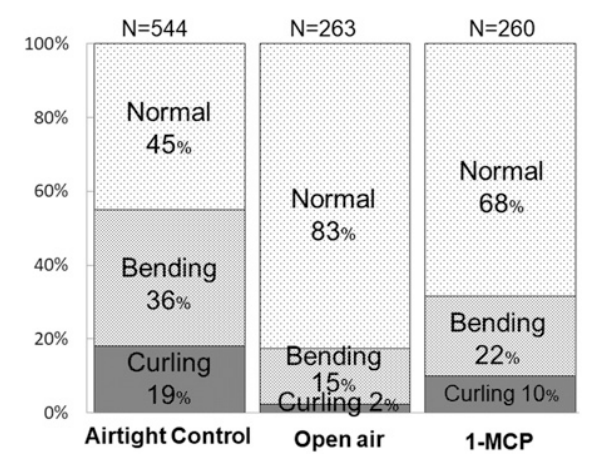

Fig. 3. Proportions of each category of cotyledons in airtight control, open air, and 1-MCP. N represents total number of cotyledons in each condition. Data come from six (airtight control) or three (open air, 1-MCP) independent measurements. The percentages of each category were calculated. Differences between airtight control and open air, and between airtight control and $1-\mathrm{MCP}$ were significant in all categories at $P<0.05$ by $\chi^{2}$ test and residual analysis. 
Table 1. Atmospheric concentrations of ethylene.

\begin{tabular}{lc}
\hline & $\begin{array}{c}\text { Concn of ethylene }(\mathrm{nmol} / \mathrm{L}) \\
(\mathrm{mean} \pm \mathrm{SEM})\end{array}$ \\
\hline Airtight control & $3.7 \pm 0.34$ \\
Open air & 0 \\
1-MCP & $6.3 \pm 0.55$ \\
\hline
\end{tabular}

Each container held 70 seeds and used three containers in airtight control and four containers in 1-MCP, respectively. Ambient air was sampled for open air treatment. The means in airtight control and 1-MCP were based on three and four biologically independent measurements, respectively.

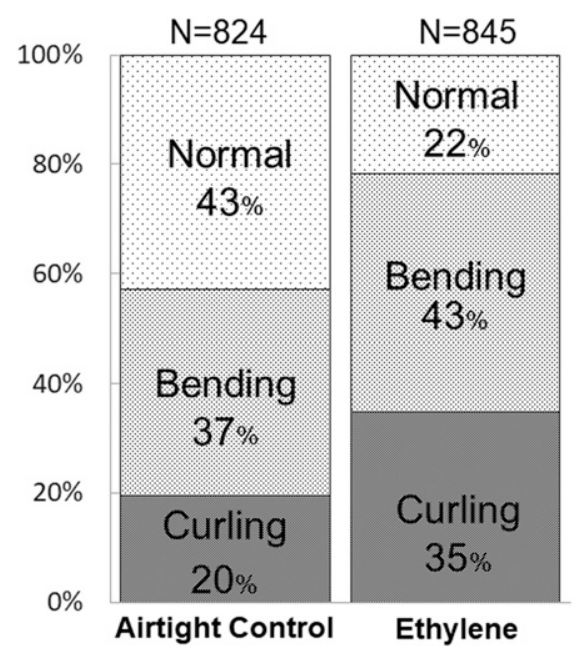

Fig. 4. Effect of exogenous ethylene on cotyledon curling. $\mathrm{N}$ represents total number of cotyledons in each condition. Data in each treatment come from five independent measurements. The percentages of each category were calculated. In all categories, differences were significant at $P<0.05$ by $\chi^{2}$ test and residual analysis. Ethylene $=0.89 \mu \mathrm{mol} / \mathrm{L}$ ethylene.

sides of normal and curled cotyledons in transverse direction (Fig. 5A). On the adaxial side, the mean was 224.8 cells in normal cotyledons and 239.7 cells in curled cotyledons; on the abaxial side, the mean was 155.3 cells in normal cotyledons and 181.7 cells in curled cotyledons. In both sides, there were no significant differences on either side in the mean number of cells in the transverse direction between normal and curled cotyledons (Fig. 5A).

We calculated the cell width on the adaxial and abaxial sides (Fig. 5B). On the adaxial side, the width was $20.6 \mu \mathrm{m}$ in normal cotyledons and $18 \mu \mathrm{m}$ in curled cotyledons. No significant difference was observed. On the abaxial side, however, the width was $29.7 \mu \mathrm{m}$ in normal cotyledons and $18.8 \mu \mathrm{m}$ in curled cotyledons $(P<0.05)$. Thus, cells of curled cotyledons were smaller than those of normal cotyledons on the abaxial side $(P<0.05)$, but not on the adaxial side (Fig. 5B).

We measured the thickness of cotyledons in six parts $(\mathrm{A}-\mathrm{F})$ to investigate growth in the dorsoventral direction. In part $\mathrm{B}$, the thickness was $325 \mu \mathrm{m}$ in normal cotyledons and $447 \mu \mathrm{m}$ in curled cotyledons $(P<0.05)$. There were no significant differences on part $\mathrm{C}(P<0.10)$ and parts $\mathrm{A}, \mathrm{D}, \mathrm{E}$, and $\mathrm{F}$

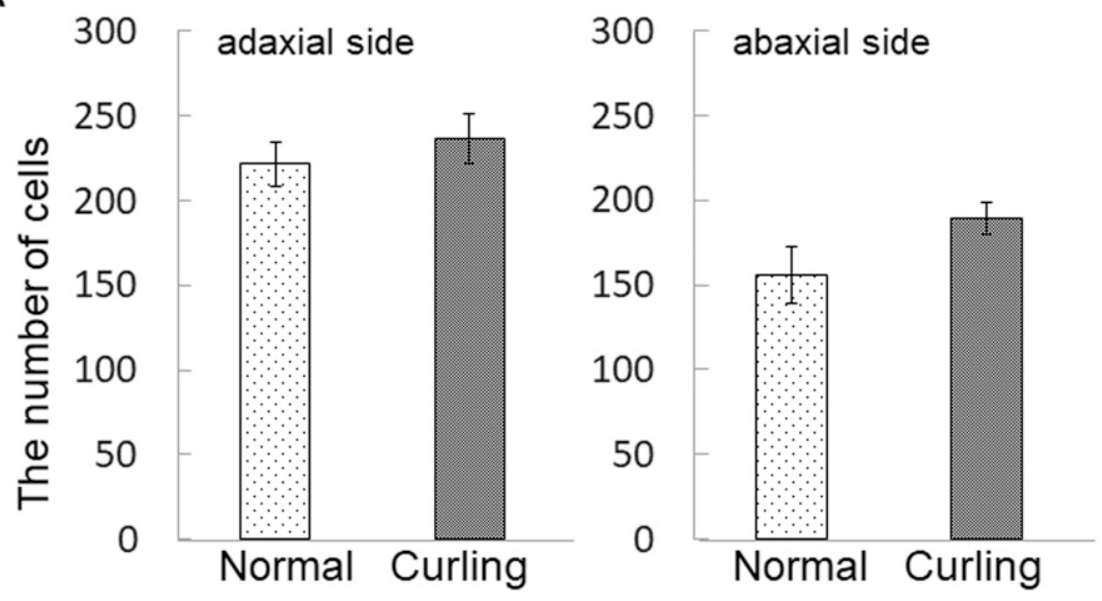

B
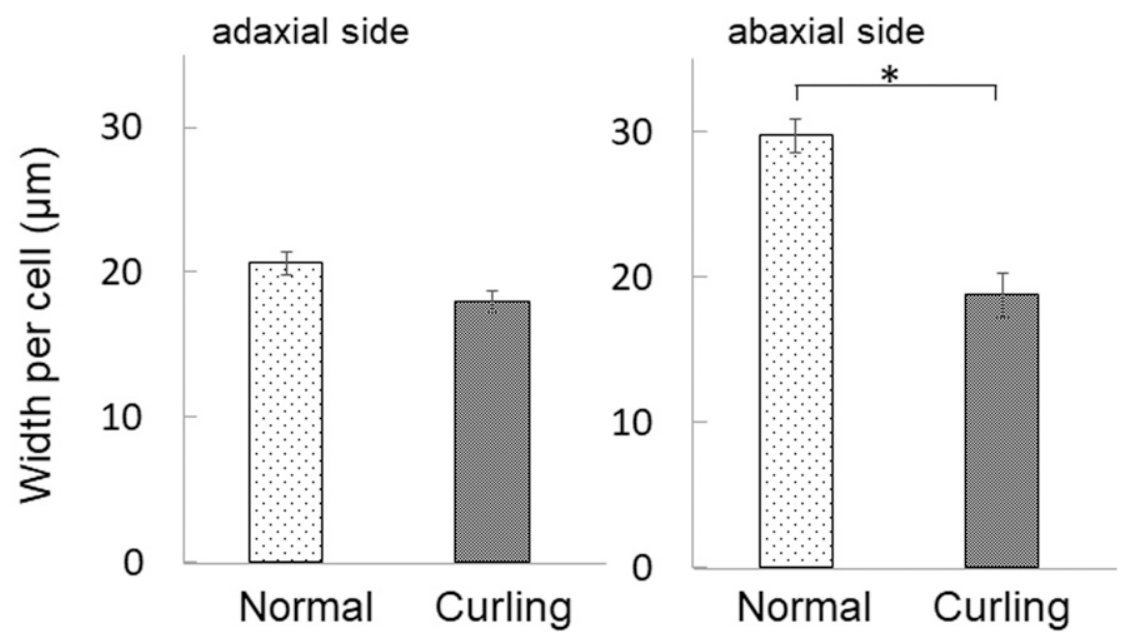

Fig. 5. Measurement of cell numbers and cell width in transverse direction in normal cotyledons in airtight condition and curled cotyledons in ethylene treatment $(\mathrm{n}=3$ each). (A) Numbers of cells. Differences were not significant by $t$ test. (B) Cell widths. *Significant difference at $P<0.05$ on abaxial side by $t$ test. Error bars show standard error of mean.

$(P>0.10)$ (Fig. 6A). Overall, curled cotyledons were thicker than normal cotyledons. There were no significant differences in the numbers of cells on either side of parts $A$ to $F$ in the dorsoventral direction between normal and curled cotyledons (Fig. 6B).

On the adaxial side, cell thickness in part B was $29.1 \mu \mathrm{m}$ in normal cotyledons and $45.3 \mu \mathrm{m}$ in curled cotyledons $(P<0.05)$. There were no significant differences on parts A and $\mathrm{C}(P<$ $0.10)$ and parts D, E, and $\mathrm{F}(P>0.10)$ (Fig. 6C). On the abaxial side, there were no significant differences on parts $\mathrm{A}, \mathrm{B}$, and $\mathrm{C}(P<0.10)$ and parts D, E, and F $(P>0.10)$ (Fig. 6C). Thus, in part, curled cotyledons had thicker cells than normal cotyledons.

Curling in airtight condition and curling caused by ethylene treatment are the same phenomenon at the cellular level. We investigate whether cotyledon curling in airtight condition and curling caused by ethylene treatment are same phenomenon. The sections of curled cotyledon in airtight condition and curled cotyledon by ethylene treatment were prepared. We counted the number of cells on the adaxial and abaxial sides of curled cotyledons in airtight control condition in transverse direction. On the adaxial side, the mean was 239.7 cells in ethylene treatment and 254.3 cells in airtight control. On the abaxial side, the mean was 181 cells in ethylene treatment and 187.8 cells in airtight control. In both sides, there were no significant differences between ethylene and control treatments and airtight control (Fig. 7A). We calculated the cell width on the adaxial and abaxial sides. On the adaxial side, the cell width was $18 \mu \mathrm{m}$ in ethylene treatment and $21.2 \mu \mathrm{m}$ in airtight control. On the abaxial side, the width was $18.8 \mu \mathrm{m}$ in ethylene treatment and $24 \mu \mathrm{m}$ in airtight control. In both sides, there were no significant differences between ethylene treatment and airtight control.

In addition, we compared curled cotyledon in airtight condition and normal cotyledon in airtight condition. there were no significant differences on cell number in transverse direction in both adaxial and abaxial side. however, although there was no significant difference on the adaxial side, cell width was significantly greater $(P<0.05)$ 
A

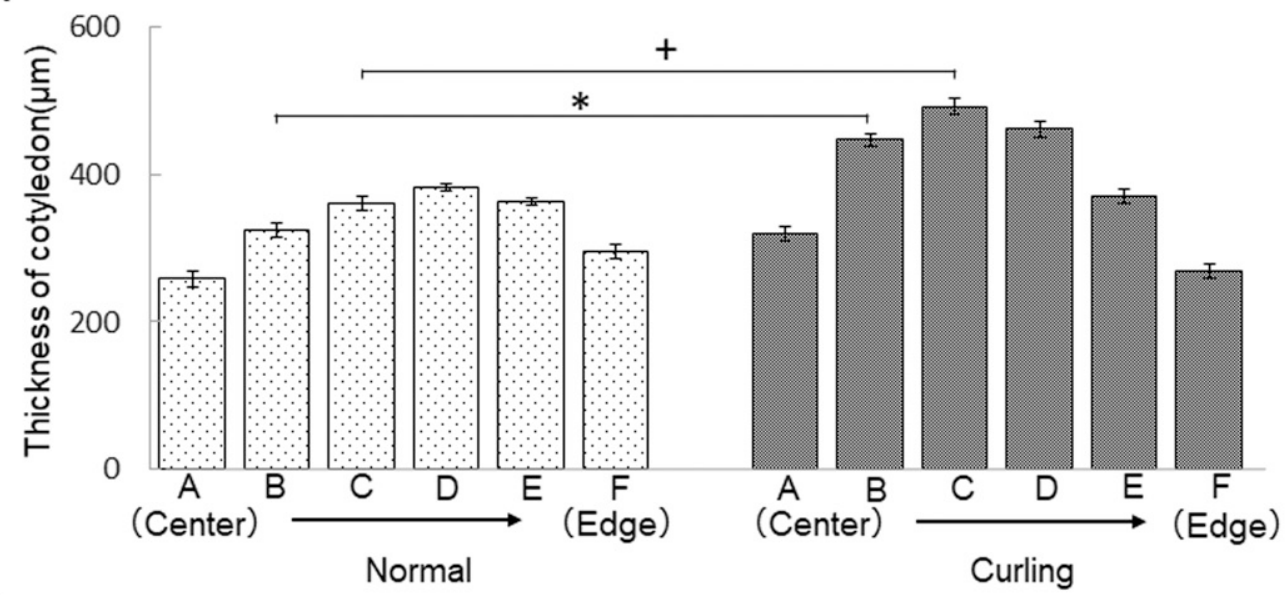

B
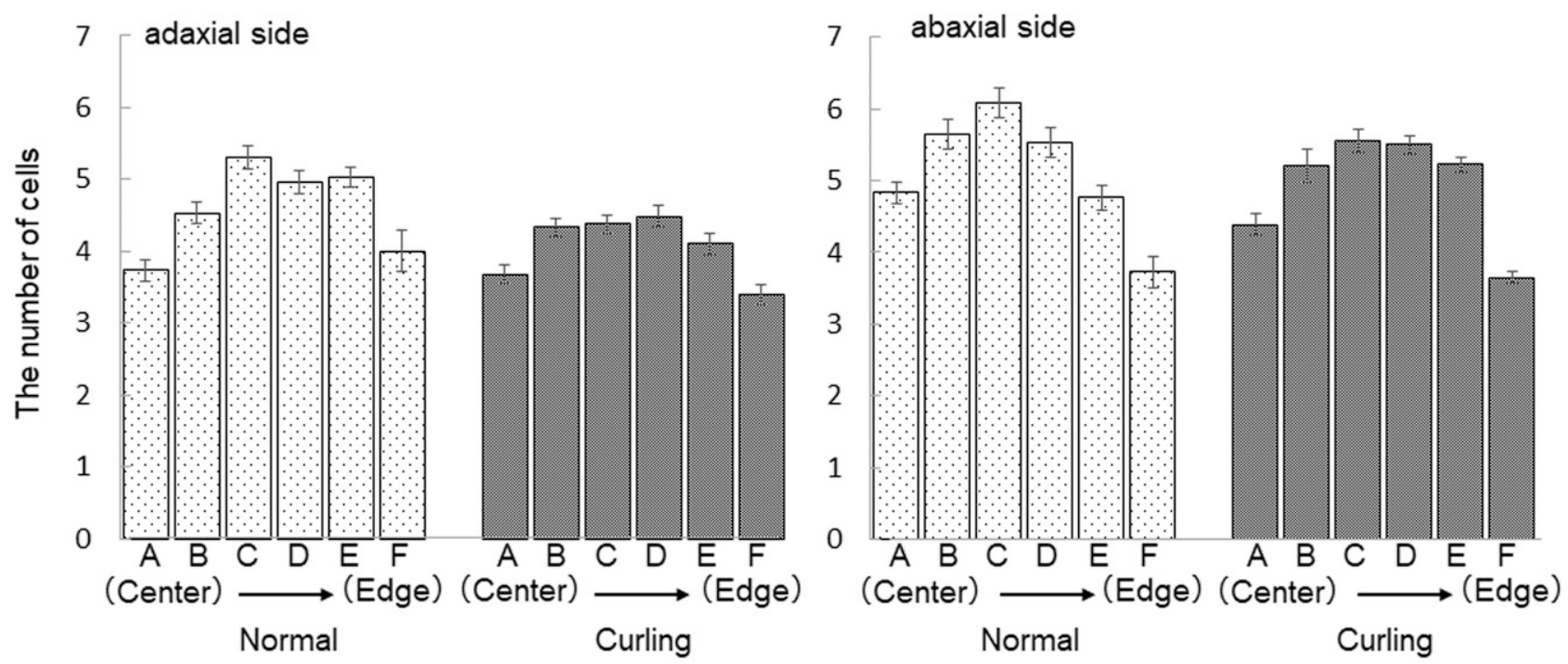

C
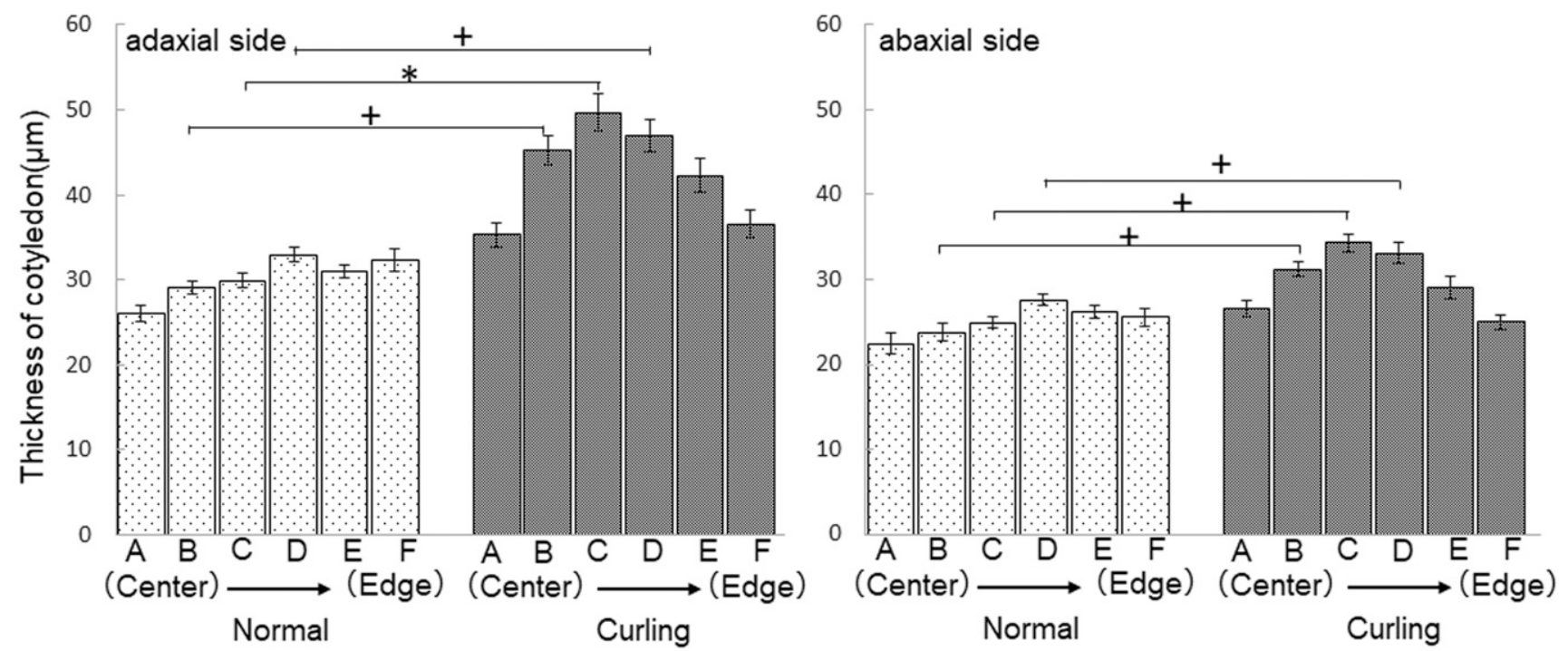

Fig. 6. Measurement of cotyledon thickness, cell numbers in dorsoventral direction, and cell thickness in normal cotyledons in airtight condition and curled cotyledons in ethylene treatment $\left(\mathrm{n}=3\right.$ each). (A) Thickness of each part. *Significant difference at $P<0.05$ by $t$ test in part B. ${ }^{+} P<0.10$ by $t$ test in part C. $(\mathbf{B})$ Cell numbers. Differences were not significant by $t$ test. (C) Cell thickness. *Significant difference at $P<0.05$ by $t$ test in part B. ${ }^{+} P<0.10$ by $t$ test in parts A and $\mathrm{C}$ on adaxial side. ${ }^{+} P<0.10$ by $t$ test in parts $\mathrm{A}, \mathrm{B}$, and $\mathrm{C}$ on abaxial side. Error bars show standard error of mean.

in normal cotyledons than in curled cotyledons on the abaxial side (Fig. 7B). These results have the same tendency with compar- ison between curled cotyledons caused by ethylene treatment and normal cotyledons in airtight condition (Fig. 5) and show that at the cellular level, the same phenomenon occurred in curling in airtight conditions and curling caused by ethylene treatment. 

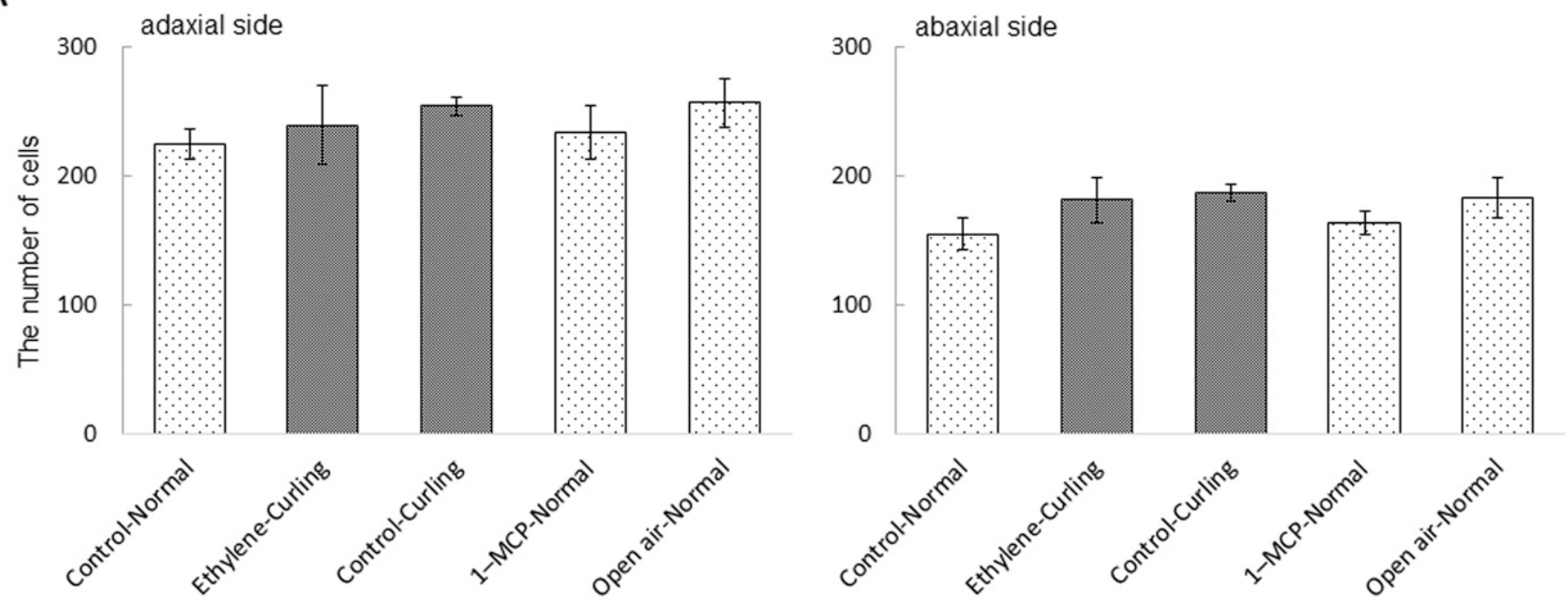

B
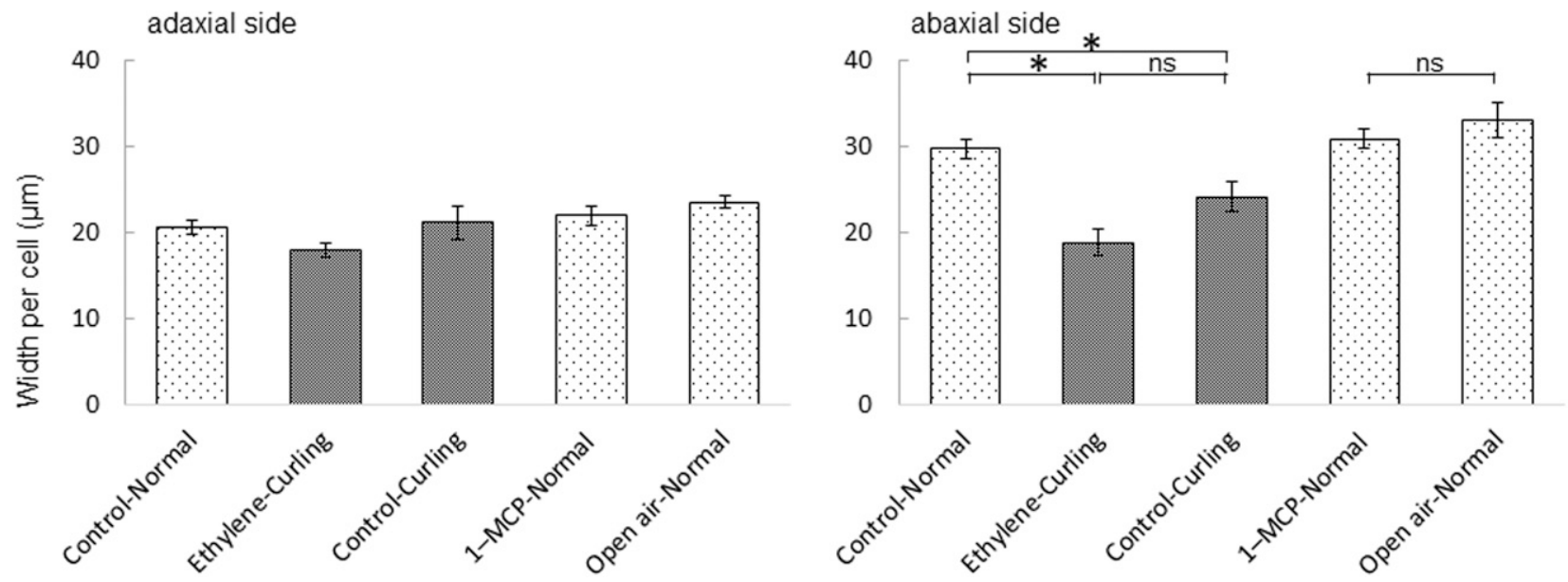

Fig. 7. (A) Number of cells in the transverse direction in three normal cotyledons in airtight condition, three curled cotyledons in ethylene treatment, three curled cotyledons in airtight condition, three normal cotyledons in 1-MCP treatment, and three normal cotyledons in open air condition. Differences were not significant $(P<0.05)$ by $t$ test. (B) Cell width in the transverse direction in three normal cotyledons in airtight condition, three curled cotyledons in ethylene treatment, three curled cotyledons in airtight condition, three normal cotyledons in 1-MCP treatment, and three normal cotyledons in open air condition. $* P<0.05$ on abaxial side by $t$ test; ns, $P>0.05$ by $t$ test. Error bars show standard error of mean.

Normal cotyledons restored by 1-MCP treatment and normal cotyledons in open air are the same at the cellular level. We investigated whether normal cotyledon caused by inhibition of ethylene-promoted curling by 1-MCP and normal cotyledon in open air condition are same in the cellular level. The sections of normal cotyledon in 1MCP treatment, and normal cotyledon in open air condition were prepared. We counted the number of cells on the adaxial and abaxial sides of curled cotyledons in airtight control condition in transverse direction. On the adaxial side, the mean was 234.5 cells in 1-MCP treatment and 257.2 cells in open air. On the abaxial side, the mean was 164 cells in 1-MCP treatment and 183.5 cells in open air. In both sides, there were no significant differences between 1-MCP treatment and open air (Fig. 7A). We calculated the cell width on the adaxial and abaxial sides. On the adaxial side, the width was $22 \mu \mathrm{m}$ in 1-MCP treatment and
$23.5 \mu \mathrm{m}$ in open air. On the abaxial side, the width was $30.9 \mu \mathrm{m}$ in 1-MCP treatment and $33 \mu \mathrm{m}$ in open air. In both sides, there were no significant differences between 1-MCP treatment and open air (Fig. 7B). These results showed that normal cotyledons caused by 1MCP inhibition of curling and normal cotyledons in open air are the same at the cellular level.

\section{Discussion}

Effects of ethylene on cotyledon curling of Japanese radish. Japanese radish sprouts sold in the market often have curled cotyledons. Our examination confirmed that the proportion of curled cotyledons was greater in airtight condition than in open air (Fig. 3). This result indicated that the factor involving cotyledon curling was in the airtight condition. What caused this curling? In airtight containers, water vapor, carbon dioxide, oxygen, and volatile compounds such as ethylene can accumulate. There is no report of the involvement of water vapor, carbon dioxide, or oxygen in cotyledon curling. On the other hand, it is well known that ethylene induces curling of leaves (Crocker et al., 1932; Crocker, 1948; Kang, 1979; Palmer, 1985). We detected no ethylene in open air, but we detected $3.7 \mathrm{nmol} \cdot \mathrm{L}^{-1}$ after $7 \mathrm{~d}$ of airtight storage (Table 1). These results suggest that ethylene affected the cotyledons of Japanese radish. Treatment with exogenous ethylene increased the proportion of curling (Fig. 4), and treatment with 1-MCP, an ethylene antagonist, reduced it (Fig. 3).

Note that the ethylene concentration was greater in the 1-MCP condition than in the airtight control, and yet curling was reduced (Table 1). It has been reported that the ethylene suppressed an increase in the level of the mRNA of 1-aminocyclopropane-1-carboxylate (ACC) synthase, but 2,5-norbornadiene, an inhibitor of ethylene action, like 1-MCP, enhanced it (Nakajima et al., 1990). In addition, transcripts of LeACS6, which encodes ACC 


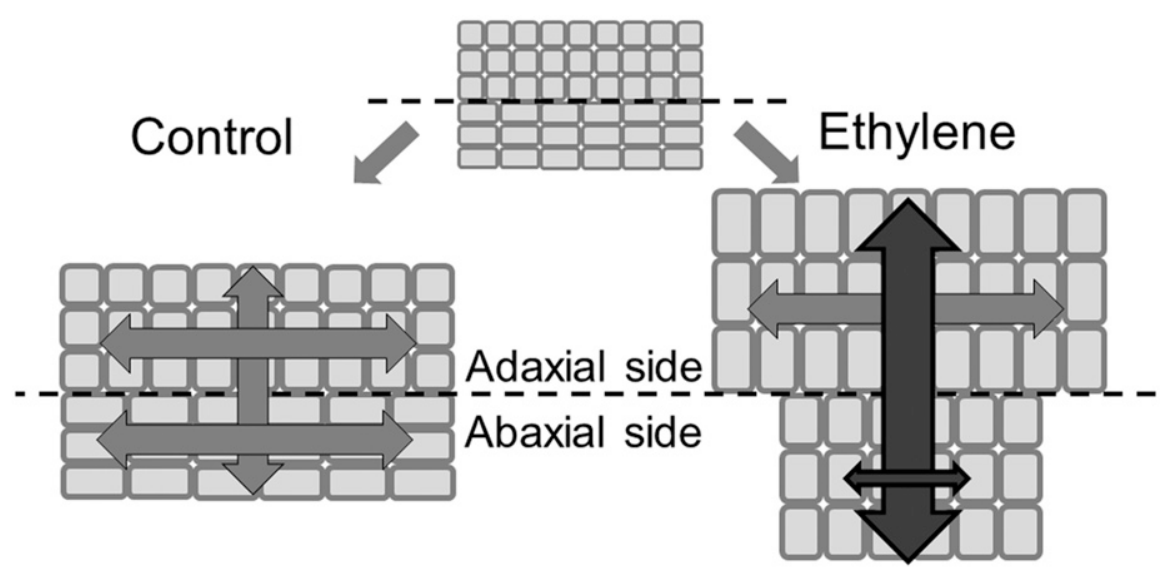

Fig. 8. Effects of ethylene on Japanese radish cotyledons at the cellular level. Above, undeveloped cotyledons. Lower left, cotyledons grown without ethylene. Lower right, cotyledons grown with ethylene. The doubleheaded arrows show the direction and degree of cell expansion. Ethylene did not affect cell division; did not affect transverse (lateral) cell growth on the adaxial side but suppressed it on the abaxial side; and promoted dorsoventral (vertical) cell growth.

synthase in tomato, were accumulated in ripening fruit treated with 1-MCP (Nakatsuka et al., 1998). In accord with these previous results, the present results suggest that 1-MCP enhanced transcription of ACC synthase genes and increased the production of ethylene, probably through the enhancement of ACC synthase gene transcripts.

Investigation of cell number and width showed that the same phenomenon at the cellular level occurred in curling in airtight condition and curling promoted by ethylene treatment (Fig. 7). Thus, endogenously produced ethylene likely caused cotyledon curling in airtight condition. In addition, normal cotyledons caused by 1-MCP inhibition of curling and normal cotyledons in open air were the same at the cellular level (Fig. 7), so the reduction of the proportion of curled cotyledons by 1-MCP (Fig. 3) is caused by inhibition of the effects of endogenously produced ethylene. Taken together, these results indicate that ethylene that accumulates in airtight condition makes cotyledons curl.

Effects of ethylene on cell division and cell growth of cotyledons. Ethylene promotes leaf curling through epinasty, which is due to the expansion of cells on the adaxial side of the leaf (Crocker et al., 1932; Crocker, 1948; Kang, 1979; Palmer, 1985). Most previous studies of epinasty tested true leaves and petioles, and there are few studies of other organs (Reid et al., 1981). Hence in cotyledons of Japanese radish, to identify the affecting process of ethylene in cellular level abaxial side of the cotyledons of Japanese radish. This study reveals a newly discovered mechanism involved in the curling of leaves caused by ethylene.

\section{Literature Cited}

Crocker, W. 1948. Physiological effects of ethylene and other unsaturated carbon-containing gases, p. 139-171. In: W. Crocker (ed.). Growth of plants. Reinhold Publishing Corporation, New York, NY.

Crocker, W., P.W. Zimmerman, and A.E. Hitchcock. 1932. Ethylene-induced epinasty of leaves and the relation of gravity to it. Contrib. Boyce Thompson Inst. 4:177-218.

Kang, B.G. 1979. Epinasty, p. 647-667. In: W. Haupt and M. E. Feinleib (eds.). Encyclopedia of plant physiology, Vol. 7. Springer-Verlag, Berlin.

Nakajima, N., H. Mori, K. Yamazaki, and H. Imaseki. 1990. Molecular cloning and sequence of a complementary DNA encoding 1-aminocyclopropane-1-carboxylate synthase induced by tissue wounding. Plant Cell Physiol. 31:1021-1029.

in cotyledon curling, the cell number and length in cotyledons with and without ethylene treatment should be considered (Fig. 8). We found no differences in cell number in the transverse or dorsoventral direction of either side of cotyledons between treatments (Figs. 6-8), so ethylene does not affect cell division. We also found no differences in transverse cell growth on the adaxial side between normal and curled cotyledons. On the abaxial side, however, cells of curled cotyledons were smaller than those of normal cotyledons. These results indicate that ethylene suppressed transverse cell growth on the abaxial side of the cotyledons. In addition, curled cotyledons were thicker than normal cotyledons owing to thicker cells. This result suggests that ethylene promotes dorsoventral cell growth, making cotyledons thicker.

\section{Conclusion}

Ethylene did not affect cell division but did inhibit transverse cell growth on the abaxial side (Fig. 8), causing cotyledon curling. It also promoted dorsoventral cell growth, especially around the central axis, although this was not involved in curling. Ethylene promotes curling of tomato leaf petioles by epinasty (Crocker et al., 1932; Crocker, 1948; Kang, 1979; Palmer, 1985). Its mechanism involved ethylene promoting transverse cell growth on the adaxial side (Crocker et al., 1932; Crocker, 1948; Kang, 1979; Palmer, 1985). We showed that ethylene inhibits cell growth on the
Nakatsuka, A., S. Murachi, H. Okunishi, S. Shiomi, R. Nakano, Y. Kubo, and A. Inaba. 1998. Differential expression and internal feedback regulation of 1-aminocyclopropane-1-carboxylate synthase, 1-aminocyclopropane-1-carboxylate oxidase, and ethylene receptor genes in tomato fruit during development and ripening. Plant Physiol. 118:1295-1305.

Palmer, J.H. 1976. Failure of ethylene to change the distribution of indoleacetic acid in the petiole of Coleus blumei $\times$ frederici during epinasty. Plant Physiol. 58:513-515.

Palmer, J.H. 1985. Epinasty, hyponasty, and related topics, p. 139-168. In: R.P. Pharis and D.M. Reid (eds.). Encyclopedia of plant physiology, Vol. 11. Springer-Verlag, Berlin.

Reid, M.S., Y. Mor, and A.M. Kofranek. 1981. Epinasty of poinsettias-The role of auxin and ethylene. Plant Physiol. 67:950-952.

Sisler, E.C. and M. Serek. 1997. Inhibitors of ethylene responses in plants at the receptor level: Recent developments. Physiol. Plant. 100:577-582.

Statistics Bureau of Japan, Ministry of Internal Affairs and Communications. 2014. <https://www. e-stat.go.jp/stat-search/files?page=1\&layout= datalist\&stat_infid $=000025450285 \& 1$ id $=$ 000001119552>.

Sumiyoshi, M., T. Inamura, A. Nakamura, T. Aohara, T. Ishii, S. Satoh, and H. Iwai. 2014. UDP-arabinopyranose mutase 3 is required for pollen wall morphogenesis in rice (Oryza sativa). Plant Cell Physiol. 56:232-241.

Ursin, V.M. and K.J. Bradford. 1989. Auxin and ethylene regulation of petiole epinasty in two developmental mutants of tomato, diageotropica and epinastic. Plant Physiol. 90:13411346. 